authors themselves then announce that they are going to abbreviate the latter to dinosaurs!).

To my mind, this is absurd. Classifications have purposes other than the indication of direct ancestor-descendant relationships. What is wrong with naming groups, especially stem-groups, that we all have to use all the time? Moreover, I am genetically much closer to my first cousin than to my descendant a thousand generations down the line, and the logical conclusion of a Russian-doll type of classification is that I am a blue-green alga. But this is not the place for an orgy of cladist-bashing; the authors are entitled to do it their own way, at present so fashionable among the younger palaeontologists of North America.

What is deplorable, however, is the redefinition of existing words, words in frequent use, to mean something utterly different. Even more confusing is the indiscriminate use of such words in both senses. Thus 'monophyletic' is used to describe the Sauropoda as "evolved from a single ancestor" (Ernst Haeckel's original definition, correct etymologically and in every other way; antonym 'polyphyletic'). Four lines later, however, the term is applied to the Prosauropoda in a context where it can only mean "including all its own descendants, without end" (as redefined much later by Willi Hennig; antonym 'paraphyletic'). Meanwhile, the authors have every right, since they so wish, to split the Amniota vertically into Reptilia (excluding mammallike reptiles and including birds) and Synapsida (including mammals); but why misuse those familiar names - especially as Edwin Goodrich had invented new names for the same groupings, Sauropsida and Theropsida respectively, some 80 years ago?

I have some further brief comments. Most important, there is no indication of how a dinosaur is defined, beyond a statement that all dinosaurs share a host of derived characters; most of those are wrong, and a few others that are correct have been omitted. It is also stated that the earliest dinosaurs were "irrevocably bipedal" (which sits strangely with the following statement that all quadrupedal dinosaurs are secondary reversions); there is not a shred of evidence for any of this. Replacement of the term "fully improved" limb posture by "fully erect" is misleading; students often confuse "erect" with "bipedal" (which, of course, it isn't) and the potential misconception is reinforced by the figure on page 83 . The origin of the dinosaurs, no later than the Carnian, could hardly have been induced by the much later alleged extinctions in the Late Triassic; their supposed derivation from the lagosuchids is also unsupported by any real evidence. There is no mention of dinosaur finds before 1818, such as Reverend Dr
Robert Plot's Megalosaurus femur from Oxfordshire (1676) or William Smith's Iguanodon tibia from East Sussex (1809). With regard to predator-prey ratios, the number of skeletons available for fossilization is in inverse proportion to the unknown length of the average life span (is this what the authors rather obscurely refer to as "turnover"?); the number can therefore tell us nothing about the size of the living population, which fact alone renders Robert Bakker's method useless as an indicator of endothermy and makes all the other uncertainties superfluous. Surprisingly, the authors favour a catastrophe theory for the extinction of the dinosaurs; their attempted refutation of the principal objection to all catastrophe theories, namely that many major groups of animals and plants survived the supposed extinction event virtually unscathed, is far from convincing.

Despite my severe criticisms on certain specific points, I still think that this is the best introductory textbook for students. It is also extremely useful to the specialist; I only wish it were better referenced. Even so, I would not be without it.

Alan Charig is an active retired worker (former chief curator of fossil reptiles and birds) in the Department of Palaeontology, The Natural History Museum, London SW7 5BD, UK.

\title{
Global movers and shakers
}

\section{Jean-Pierre Burg}

Tectonics. By Eldridge M. Moores and Robert J. Twiss. W. H. Freeman: 1995. Pp. 415. \$59.95, £29.95.

IN the seventeenth century, naturalists began to see structures (structurae in Latin) in rocks. These structurae were considered to be primary features, acquired while rock layers were being deposited, but the term was quickly extended to deformation features that nearly 200 years later were established to be tectonic structures (the ancient Greek $\tau \varepsilon \chi \tau o v \imath \kappa \eta$ means art of building). Ever since, the academic difference between structural geology and tectonics in the study of the 'architecture' of the Earth has been blurred. Although structural geology does not exclude a geological object because of its size, tectonics generally deals with the larger features. The title Tectonics stems from these intricate semantics, and duplications of text and figures found in the authors' companion Structural Geology (W. H. Freeman, 1992; for a review see Nature 361, 416: 1993) do not help to clarify the distinction.

Structural geologists overcame a large psychological barrier with their discovery of evidence of horizontal forces and movements. Using the distribution of mountain ranges to define belts of continental shortening, and fold orientations to determine the force directions, they imagined slow yet small motions between continental blocks. A few visionary geologists embraced the idea of continental drift developed by Alfred Wegener in 1915. But they were unable to prove the existence of plate movements because they needed to explore the oceans, not the continents, to find convincing arguments.

E. M. Moores and R. J. Twiss reflect on the setbacks that have paved the path to success of plate tectonics and comprehensively document how the return of research to the sea, successfully done by geophysi- cists in the 1960s, was vital for teaching us about the versatility of the Earth's outer shell. They make this point before these historical considerations, by describing most of the geophysical techniques and discoveries that brought about a conceptual revolution in the Earth sciences. The text avoids jargon, and technical terms are defined in footnotes and boxes. The foundations of plate tectonics are solidly laid out through an interpretation of the recent, large-scale features of the Earth in terms of relative movements (the kinematics) and forces (the dynamics). Plates collide and compression dominates at convergent plate boundaries; plates are pulled apart and tension dominates at divergent plate boundaries; and plates slide horizontally past each other and shearing dominates at transform plate boundaries. Each of these three tectonic settings and the resulting characteristic structures are accurately reviewed.

The authors are less successful in their treatment of the case studies of orogenic belts. For example, in the past ten years structural geologists have shown that thickened continental crust may deform in response to forces other than those due to plate motions. Regrettably, this is not considered by the authors. Nor do they describe a few key techniques for understanding large-scale structures such as numerical modelling. Had they avoided the duplications mentioned above, the authors would have had the space to cover the latest tectonics research and so produce a stronger reference for undergraduate and graduate students as well as scholars. Nevertheless, every reader will grasp and appreciate the knowledge presented in this clear, generously illustrated companion to Structural Geology.

Jean-Pierre Burg is at the Geologisches Institut, ETH-Zentrum, Sonneggstrasse 5, $\mathrm{CH}-8092$ Zürich, Switzerland. 